mens. A small supplementary note on the appearance and diagnostic value of elastic fibres in the sputum completes the first part of the work, and a very complete literature of the subject, with abstracts of the individual papers or of groups of papers, is appended. This should prove of special value to anyone working $a b$ the subject, or to anyone interested in the history of the development of the tubercle bacillus question. The plate of thirty-one figures appears to be accurately drawn and reproduced.

The Frog: an Introduction to Anatomy, Histology, and Embryology. By A. Milnes MaRshall, M.D., F.R.S., Professor in the Victoria University. Fonrth Edition, Revised and Illustrated. Pp. 163. Manchester: J. E. Cornish. London : Smith, Elder, and Co. 1891.-We have already had occasion to notice with approval this excellent little manual, and are glad to find that it has been found so useful as to demand the issue of a fourth edition. The description of the animal is preceded by a short chapter supplying hints to the student on the instruments required, the mode of dissection, and the preparation of microscopical objects. The work is thoroughly adapted for study, and the directions for the display of the several parts are so clear that they may be followed by the youngest student without assistance. There are nine chapters, which are arranged in the following order: the General Anatomy of the Frog; the Vascular System ; Elementary Histology ; the Skeleton; the Muscular System; the Nervous System; the Eye and Ear; the Reproductive Organs ; and, lastly, the Development of the Animal. There are thirty-six illustrations, some of which-as that of the heart and those exhibiting the process of development-are very good.

Moderne Chemie. Von Dr. LAssaR.COHN. Hamburg und Leipzig : Leopold Voss. 1891.-In this brochure the more recent advances that have been made in chemical science are discussed, and much of the space is accordingly devoted to an account of the composition and structure of new compounds like antipyrin, antifebıin, and phenacetin, which are of especial interest to medical men. The work in reality consists of twelve lectures written for the enlightenment of those physicians who may wish to keep pace with modern chemical notions. In Chapter VIII. will be found an excellent argument on Emil Fischer's dis. covery of the synthesis of glucose. Briefly, it may be of interest to add that the synthetic process consists in the conversion of d-mannonic acid, $\mathrm{C}_{6} \mathrm{H}_{12} \mathrm{O}_{7}$, into gluconic acid, $\mathrm{C}_{6} \mathrm{H}_{12} \mathrm{O}_{7}$, which is effected by heating the former with quinoline and water. (Mannonic acid is an oxidation product of mannite.) The gluconic acid is purified by treating with phenyl-hydrazine, $\mathrm{C}_{6} \mathrm{H}_{5} \mathrm{~N}_{2} \mathrm{H}_{3}$, then converting the hydrazide into the calcium salt and decomposing this by precipitation with oxalic acid. By a suitable treatment with sodium amalgam $\left(\mathrm{C}_{6} \mathrm{H}_{12} \mathrm{O}_{7}+\mathrm{H}_{2}=\mathrm{C}_{6} \mathrm{H}_{12} \mathrm{O}_{6}+\mathrm{H}_{2} \mathrm{O}\right)$ the gluconic acid yields a sugar which, after sufficient purification, corresponds in every respect to pure glucose. We commend this little work to those of our readers who can find time to devote some attention to the interesting modern facts and theories with which it deals.

Is the October and November numbers of the Veterinarian the reports of Section 3 of the International Congress of Hygiene and Demography are continued. The addresses given at the opening of the session at the various veterinary colleges in England and Scotland are reported, and also an account of the interesting celebration of the cen. tenary of the Royal Veterinary College. Professor Wortley Axe contributes a report of the epidemic of diphtheria at East Croydon, with special reference to its relation to an eruptive disease of the cow, which will be read with interest. Mr. W. Awde, President of the South Durham and North Yorkshire Veterinary Medical Association, referring to the recent discussions at the Congress of Hygiene, tells us that the inspection of slaughter-houses and meat as at present carried out is a farce, and that under the existing system of licensing private slaughter-houses it is impossible for the inspector to do more than cursorily examine the animals. This from such an authority is somewhat disturbirg. An interesting note on suppuration and its relation to scirrhous cord and strangles is given as read by Profese or $\mathrm{M}^{\prime}$ Fadyean before the Midland Counties Veteri. nary Medical Association. The reprints from other journals are of considerable interest.

\section{"REMOVAL OF FRAGMENT OF STEEL FROM RETINA BY MEANS OF ELECTRO- MAGNET."}

To the Editors of THE LANCET.

SIRS,-In recording a case of removal of a fragment of steel from the retina in your issue of Oct. 24tb, I stated : "So far as can be accertained, the only case previously recorded of successful removal from the retina are those of Cralezowski and Hirschberg." I should have added after "successful removal" the words "with retention of useful vision." In my mind the removal, to be successful, necessitated such result. I was aware that others had attempted and succeeded in removing fragments so situated by means of the electro magnet, but up to the time I communicated my report, which was in January, 1891, the two I mentioned were the only cnes of which I could find records in which useful rision was retained. Mr. Snell records three cases in which he attempted to remove foreign bodies from the retina; in all of these he failed to remove it. In a fourth case, where a fragment had been fixed in the retina, he removed the fragment "some months later," after the foreign body had shifted its position and was presumably lying free in the vitreous. A correspondent in your issue of Oet. 31st kindly gives a reference to a note of Knapp's, but on referiing to it $I$ can find no reference to any such success. ful operation. Mr. Snell tells me he has recorded another case of removal from the retina, but I can find no mention of it in his published cases, and he does not tell me what the resuliing vision was. $\mathrm{He}$ also informs me that Stevens has recorded a case, but this $I$ have not been able to refer to. Dr. Meighan's case was of course not recorded at the time I wrote my report. It would add much to the interest of his case if he stated whether vision was preserved, and, if so, what amount. Dr. Ferdinands of Aberdeen has written to me, telling me of a case in which he removed a fragment from the retina with temporary retention of vision. He states that six months after dismissal the patient returned with " dense white cataract," but does not state whether any visual perception was retained at that time.

In my correspondence with Mr. Snell, I find that what I considered a distinct modification of his instrument was a modification he had at some time already adopted, though it is not mentioned in his description of the instrument, and, so far as my adoption of it was concerned, was the result of a hint from one of the Cantor Lectures of 1890 . In further justification of my idea that the modification was new, I may say that I showed Mr. Snell a rough plan of it at the Ophthalmological Scciety's meeting in January, 1891 , and he at that time did not apparently recognise it as his own modification. In all other essentials, save the "collar" prolongation of the posterior pole, the instrument is after Mr. Snell's published pattern. I may say that the patient operated on in the case I recorded still retains his useful vision. - I am, Sirs, yours faithfully,

Cardiff, Nov. 9th, 1891.

J. TATHAM Thompson.

The VICTORIA Hospital For Childoren, CHELSEA. - With the object of endowing a cot in this hospital, the members, associates, and graduates of "The Children's Salon "have taken Prince's Hall, Piccadilly, for Jan. 13th and 14th, when they will be "At Home" to their friends. Only children will take part in the entertainment, particulars of which may be had of Captain Blount, the secretary, at the hospital. 